\title{
EXPERIMENTAL OPTIMIZATION OF ANNEALING OF CYLINDRICAL BRASS CASINGS
}

\author{
Janis Gulbis, Janis Viba, Martins Irbe, Kristaps Spade \\ Riga Technical University, Latvia \\ janis.gulbis@rtu.lv, janis.viba@rtu.lv, martins.irbe@ rtu.lv, spade.kristaps@gmail.com
}

\begin{abstract}
Induction heat treatment is an important tool in metallurgy. Induction annealing is a complex yet efficient manufacturing process with great potential for quality control of produced parts. Induction annealing is rarely used, but has its place and the control methods are similar to induction hardening. It allows much greater control over convection type heat treatment and allows more easily treating only selected regions on the material. One of the obstacles with heat treatment of brass parts is that it is not possible to get a direct reading with the infrared temperature sensor off the surface, therefore making the induction method heat treatment more practical than convection, as it offers almost direct control of the amount of energy inserted into material. We used induction to stress relief and anneal a hollow brass material cylinder to the desired hardness gradient. Four types of variables were controlled until the desired result was found. They are in shape of solenoid, location of solenoid in relation to the part, maximum power used and total induction time. Hardness was measured both on the outer surface of the parts and on parts cut in half. Hardness was measured using appropriate scale measurement systems using the Vickers scale. It was found that hardness differs on the surface measurement from the measurement on the inside, yet there seems to be a certain correlation on the differing amount. Induction offers a very quality controllable process with little difference in hardness form part to part. Empirical optimization is very time consuming and investing time in creating a mathematical model to do the bulk of optimization could be worth it.
\end{abstract}

Keywords: induction heat treatment, induction annealing, metallurgy, experimental optimisation.

\section{Introduction}

Induction annealing may have different roles to fill. Thermal induction treatment is heating and cooling of metallic material or alloy to obtain the desired metallurgical properties and structures (Fig.1) [1]. This is the process of using heat induction to make the material more plastic, to make it more workable. The precision used by induction heaters is ideal in modern conditions where small tolerances are required. A wide range of ready-made induction heat treatment systems have been manufactured and can be purchased for various thermal processes. These induction heating systems can be configured with different numbers of coil turns (Fig. 2) [2]. In this case, it is a part of brass casing drawing and cold forging process. Brass case forming is a complex endeavour. It involves several stamping processes with the need to stress relieve or anneal in between: drawing, necking, coining, and ironing. Every time the material is formed, it undergoes work hardening. For it to be continually formed without material cracking it needs to be stress relieved. When all the stamping steps are done, certain highly formed zones of the finished part need to be annealed. It is done to prevent from cracking over long storage periods due to internal stresses (Fig. 3) [3].

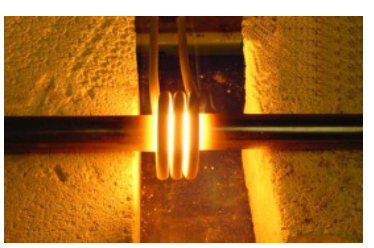

Fig. 1. Coil with three turns

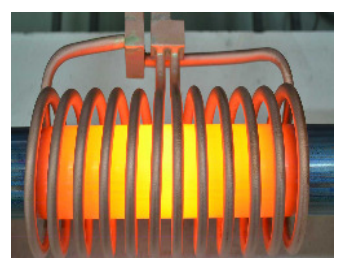

Fig. 2. Coil with
twelve turns

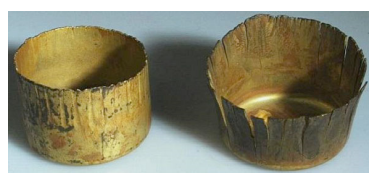

Fig.3. Brass cracking

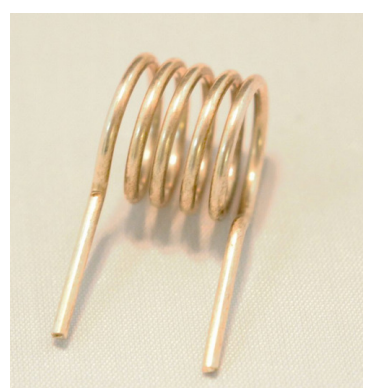

Fig. 4. Induction five windings coil

Here we look at a less familiar metalworking process: induction annealing. Although the basic principles of operation do not differ much from induction hardening, popular with gear manufacturing, induction annealing is a process not as widely known and practiced [3-7].

The main task of the new technological process optimization is to find the parameters that provide the greatest (or smallest) value to the selected criterion. If the process is new or little known, or does 
not have a mathematical model, experiments should be carried out. This approach is described in the works [8-14]. Focus on practical methods for solving real engineering optimization problems of specific optimization examples for induction heater modes and designs, particularly those used in industrial applications are investigated [6]. The book [7] contains clear explanations of high-level concepts as well as the mutual relationships between the essential ideas of the electromagnetic theory. Starting with the fundamentals of electrodynamics, it methodically covers a wide spectrum of research and applications that stem from electromagnetic phenomena, before concluding with more advanced topics, such as quantum electrodynamics.

The method of optimal synthesis of new, unknown processes or techniques is proposed [8]. This method has several steps to finding the optimal solution, for example, the first step is the preliminary analysis of the process and the experiment. An appropriate approach is described in the work [9]. In this work application of metamodeling methods for optimization included several steps: 1) design of experiments, 2) numerical experiments based on FEM calculations, 3) high precision approximations of experimental data using polynomials, locally weighted polynomials and kriging, 4) multi-objective optimization using three criterions. The results of different metamodeling methods and parameter fitting techniques were compared with a conclusion that kriging gives the best overall approximation results. According to the theory [8;9], the efficiency of the application of the optimal synthesis method is confirmed in the works [15-16]. In our study, the first step in the experimental optimization is carried out below.

\section{Materials and methods}

Induction heating happens, when high frequency alternating current is passed through a solenoid that creates a magnetic field inside it [1-6]. Mayor advantages of the induction process are fast heating cycles suitable for high volume production, potential for localizing the heating to desired areas of the part, great repeatability ensuring strict quality control for every single part. In addition, the induction method can be easily integrated into a running production line. This can be done as the transformer, its management and the cooling system can be set up almost remotely, only connecting with some wires and cooling lines to the solenoid and its secondary coil box that needs to be a part of the feeding line.

Main hurdles are the long and hard to predict lead-time on setting up the coils. Each one needs to be designed and tested for specific material and particular task. For continuous repeating use the coils are made from copper tubing (Fig. 4), so the cooling liquid can be circulated through it for the solenoid not to overheat and burn up.

\section{Optimization process}

Material hardness was measured by the Vickers method (HV - Hardness Vickers scale). The parts were measured both on the outside surface and also on the inside of the material. The parts were cut in half, grinded to a smooth surface to relief cutting induced imperfections, which would affect the measurement. Then measurement was taken on this smooth cut surface.

The first task of the optimization was to find the right shape of the induction coil. Experiments were conducted with coils with two, three, four, five and seven windings.

In order to widen the heat treated zone the experimental setup was also created where the part was heated in two steps immediately one after another, by moving the part relative to the solenoid inbetween the heating steps. This experimental setup was tested simultaneously to save time. However, since optimal single step in the heating method was found, the two-step heating solution was abandoned. Yet, in different application it could have its merits, if long parts are involved with uneven hardness requirements.

\section{Material}

Material that was heat-treated - brass CuZn30: copper 69-71\%, zinc $\sim 30 \%$, the rest of composition made up of: $\mathrm{Fe}, \mathrm{Pb}, \mathrm{Sn}, \mathrm{Al}$, and $\mathrm{Ni}$. In this state before any treatment or forming: yield strength around $150 \mathrm{MPa}$, Vickers hardness of $55-90 \mathrm{Hv}$, melting point $954^{\circ}$ [5].

An interesting obstacle with this material in planning heat treatment is a phenomenon of low thermal radiation of the smooth surface of brass. This does not allow reliable and constant reading of 
the material temperature using the infrared thermometer. It is also hard to integrate a tactile thermometer into a production line. Therefore, this is another pro for using an induction method for thermal heating, since it allows direct control over the energy output negating the need to check the temperature of the material on every heating cycle.

Another interesting quirk of the material is the colour change after heat treatment. When material is overheated and is therefore ruined, it can be guessed accurately because of its colour change. When overheated, zinc burns out of the part and the colour turns to white. The whiter it gets, the more it has been overheated until it starts to literally vanish altogether. Yet, also another interesting observation regarding colour: when treated properly, it may display a different set of surface colours depending on the frequency used in the induction heating. Even when the resulting hardness is the same with different frequencies used, it may become either brown, purple or silver. This colouring can also usually be washed off. It happens so, as the surface layer usually concentrates around $86 \%$ of the power [6].

\section{Workpiece}

The brass casings are formed in several steps starting from a flat piece of the sheet. During the forming, the materiel is stress relieved and annealed several times. When the part has finally reached its final length, it is stress relieved in a convection furnace, giving the final hardness for the first $20 \mathrm{~mm}$ measuring from the closed up bottom end (Fig.5, Fig.6).

Each of these heat treatments underwent their optimisation before full production, however, here we look only at the hardest to optimise the "middle step" of production. It is annealing of the 20 to $40 \mathrm{~mm}$ zones of the workpiece length (Fig.5, Fig.6). It needs to be annealed before forming of the bottleneck of the case and needs to stay within the recommended hardness graph after the final forming (Table 1).

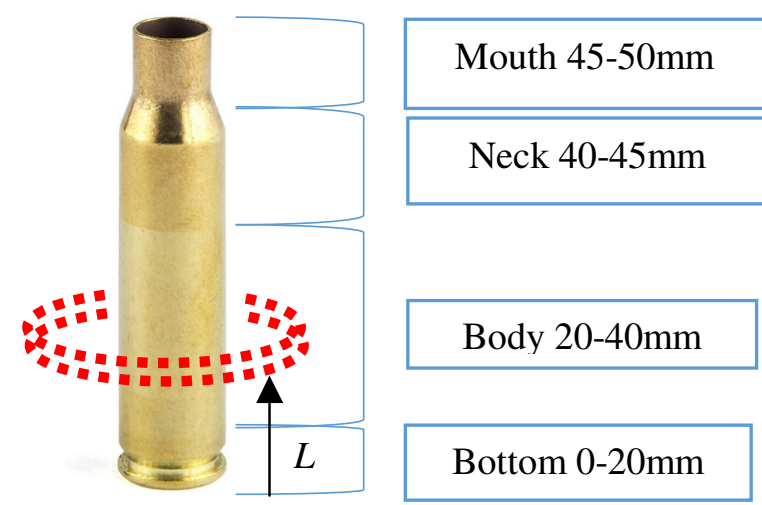

Fig. 5. Induction coil: $L-$ distance of optimization experiment point; $(0-50 \mathrm{~mm})-$ material zones

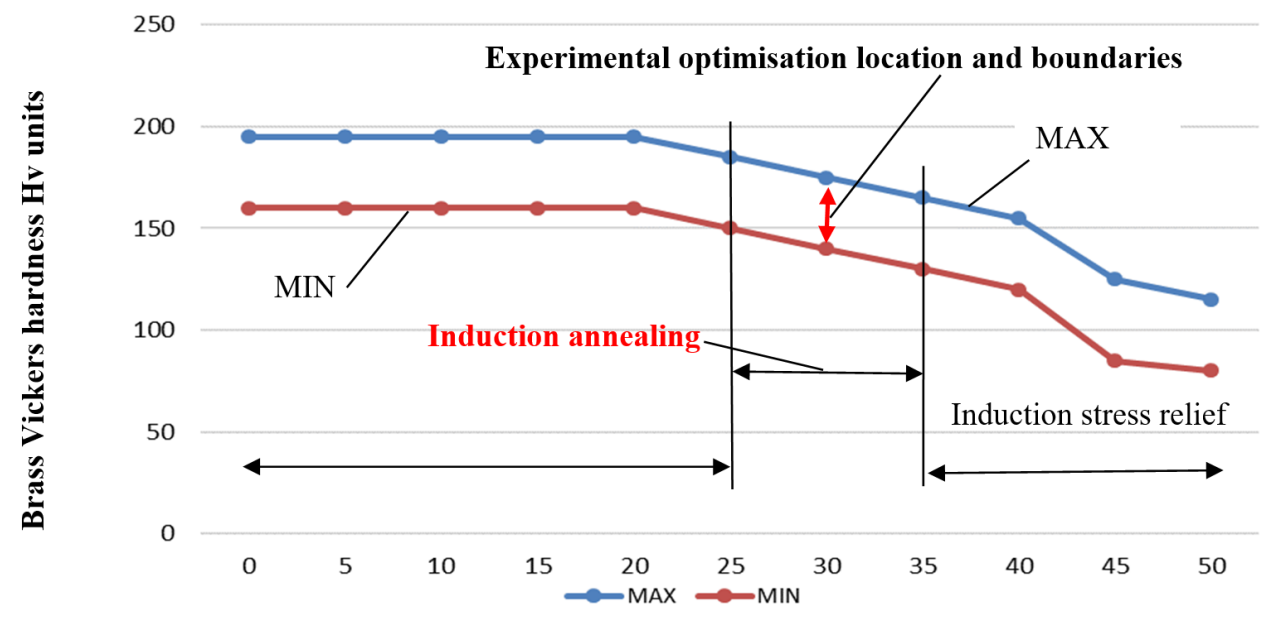

Distance $L$ in the longitudinal direction of the object in $\mathbf{~ m m}$

Fig. 6. Target Vickers Hardness (Hv) material zones and their respective technology methods: MAX - standard upper limit; MIN - standard lower limit 
The formed neck is stress relieved afterwards on its own. It is also easier to achieve the desired result faster, as it is a thinner part of the case and the end of the part. When heating the end, the heat is not pulled away like when heating the middle, therefore it is easier to control.

Taking all things in consideration, for the optimization a single point of focus was chosen at $L=30 \mathrm{~mm}$ (Fig. 6) height measuring from the bottom of the part. By achieving the necessary hardness at this point for the part, it is ensured that the rest of the part is being heat treated in the right optimum hardness range.

Table 1

Technological requirement standard and methods for obtaining it

\begin{tabular}{|c|c|c|c|c|c|c|c|c|c|c|c|}
\hline $\begin{array}{c}\text { Distance } \\
\boldsymbol{L}\end{array}$ & 0 & 5 & 10 & 15 & 20 & 25 & $\mathbf{3 0}$ & 35 & 40 & 45 & 50 \\
\hline MAX & 195 & 195 & 195 & 195 & 195 & 185 & $\mathbf{1 7 5}$ & 165 & 155 & 125 & 115 \\
\hline MIN & 160 & 160 & 160 & 160 & 160 & 150 & $\mathbf{1 4 0}$ & 130 & 120 & 85 & 80 \\
\hline Method & \multicolumn{3}{|c|}{ Stress relief in convection furnace } & \multicolumn{3}{|c|}{$\begin{array}{c}\text { Stress relief in } \\
\text { convection furnace }\end{array}$} & \multicolumn{2}{|c|}{$\begin{array}{c}\text { Induction stress } \\
\text { relief }\end{array}$} \\
\hline
\end{tabular}

\section{Experiments and methodology}

The heating machine consisted of a thin ceramic chamber, to which the solenoid is coiled around (Fig. 4). Heating machine was of $3 \mathrm{~kW}$ maximum power and operated in the range of 8 to $12 \mathrm{kHz}$.

The parts where mechanically fed with control from the same PLC, which controlled the heating cycle. A case is dropped inside, both ends closed off to prevent levitation. The part is heated and then dropped out of the bottom, the next one is then fed, and the process starts again.

An observation was made that after idle time the first workpiece is always heated differently than all the other continuously produced parts. Thus, this first part was always discarded, as the equipment is used for more or less continuous production.

For every setup tested at least 10 parts were produced. The first two were discarded and only the ones from a continuous cycle were measured.

Firstly, only two or three random parts out of the batch were measured, since the accurate method of measurement is very time-consuming cutting, grinding of the workpieces. If the results of the parts matched within the tolerance of the measuring equipment, the result was considered valid. If the results varied wildly, then another two to three parts were measured. When the amount of the measured parts was reached large enough to pick out the anomalies, the resulting statistic was analysed.

Based on the analysis, it was decided which parameter was changed for the next test. To ensure the scientific method only one parameter was changed at a given time. If the length of the heating zone was not long enough, the shape and/or the amount of turns was changed on the coil. If the hardness was not in the desired range - the power and time of heating were changed accordingly.

\section{Results and discussion}

The first order of the design was to find the right shape of the coil that would cover the entire zone that needed heat treatment. When the right length of the affected zone was found, it was discovered that the coil with 5 windings (Fig. 4) stretched to the same length, as the coil with 7 7 windings heats the same area, but with less parabolic unevenness (middle is heated more than the ends). Coils with less windings than 5 stretched to this particular length showed more uneven heating radially.

The second step was finding the right height of the coil relative to the part. To make the process a bit easier a change was made to the earlier part of the workpiece production - the parts were heated a bit longer in a convection furnace. This made the whole part with less hardness and made the existing settings overshoot the optimal hardness range (step 2 in Fig. 7) (Table 2). 
When the right configuration of the solenoid was found: length and position (Fig 4), the only parameters left to find were the power and heating time. As seen in steps 4 to 7 (Fig. 7), hardness somewhere on the softer side of the median was sought.

The final setting for power used of $3 \mathrm{~kW}$ capacity was $85 \%$ and the heating time of $1050 \mathrm{~ms}$ for heating of the 25 to $35 \mathrm{~mm}$ zone and the heating time of $1250 \mathrm{~ms}$ for the 40 to $50 \mathrm{~mm}$ zone.

Considerable amount of processed data were gathered as the first step to develop a mathematical model for multiple objective optimization.

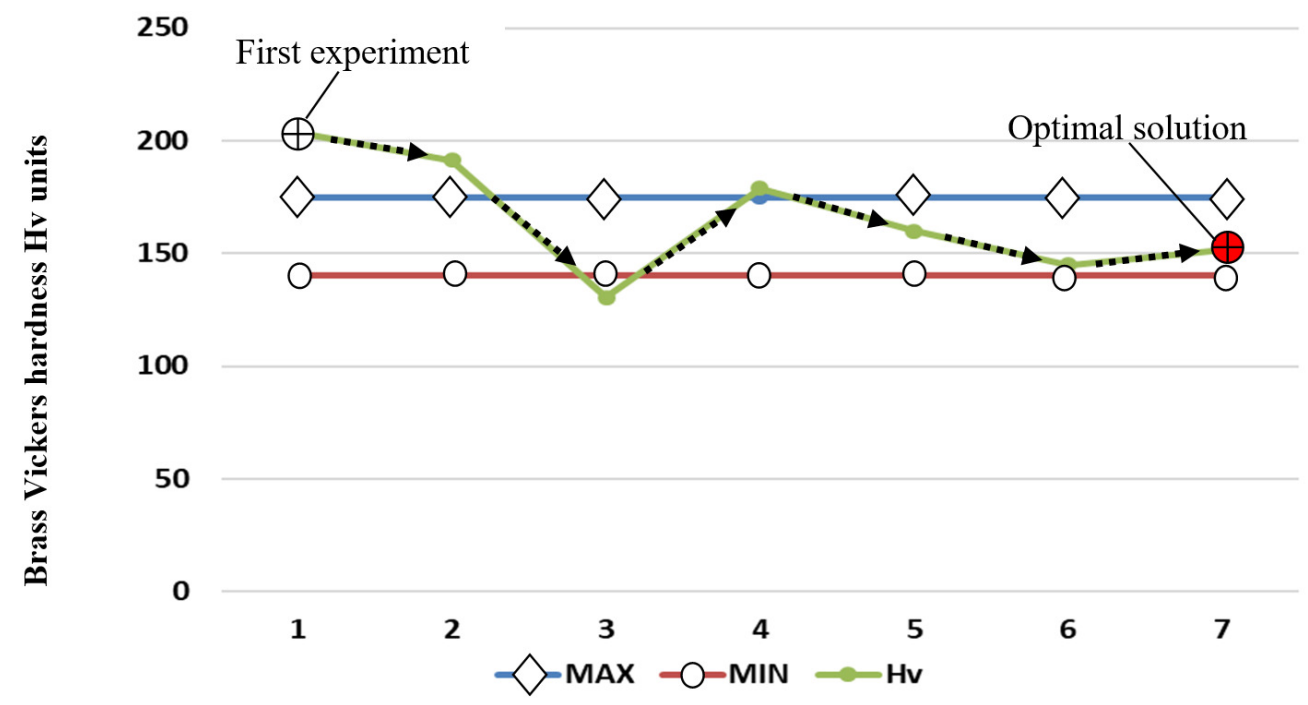

Numbers of experimental test steps $1 \div 7$

Fig. 7. Target Vickers Hardness and optimisation steps (Hv): MAX - upper limit of optimization criterion; MIN - lower limit for optimization criterion; $\mathrm{Hv}$ - obtained experiment criterion

Table 2

Optimisation steps results $\mathrm{Hv}$

\begin{tabular}{|c|c|c|c|c|c|c|c|}
\hline Parameters & \multicolumn{7}{|c|}{ Number of steps } \\
\hline Steps & 1 & 2 & 3 & 4 & 5 & 6 & 7 \\
\hline MAX & 175 & 175 & 175 & 175 & 175 & 175 & 175 \\
\hline MIN & 140 & 140 & 140 & 140 & 140 & 140 & 140 \\
\hline Hv & 203.5 & 191.3 & 130.5 & 179.0 & 160.0 & 145.0 & 151.6 \\
\hline
\end{tabular}

\section{Conclusions}

1. Induction annealing is a process that requires a certain large investment in the design. Without calculations, beforehand finding the right shape of the solenoid, is a prolonged process with unpredictable lead-time.

2. Induction heat treatment can be a production method with close to $100 \%$ quality control, given that all the related material forming processes generate parts of regular quality. This gives it a solid case for mathematical optimization for further development.

3. Distinct linear ratio of the difference between hardness of the workpiece on the outer shell and inner cut-open material was observed ranging around $15 \sim 20 \mathrm{Hv}$.

\section{References}

[1] Induction Heat Treating \& Annealing. Available at: https://rdoinduction.com/annealing.html

[2] Equipment. Available at: https://dw-inductionheater.com/portfolios/induction-annealing-heatingtreatment-equipment

[3] Stress Corrosion Cracking Brass. [online][16.02.2019] Available at: https://www.bing.com/search?q = Stress + Corrosion + Cracking + Brass\&FORM = HDRSC1 
[4] Kristen Berggen, Dr. Hansjurg Stiele. Induction Heating: A Guide to Process and Its benefits, [online][16.02.2019] Available at: http://gearsolutions.com/features/induction-heating-a-guide-tothe-process-and-its-benefits.

[5] Metals for progress. CuZn30 data sheet. Aurubis.com 2018. [online][16.02.2019] Available at: https://www.aurubis.com/en.

[6] Edgar Rapoport, Yulia PLeshivtseva. Optimal control of Induction heating processes. CRC, 2006. 349. p.

[7] Wen Geyi. Foundation of Applied Electrodynamics. Wiley, 2010. 522 p.

[8] Виба Я.А. Оптимизация и синтез виброударных машин (Optimization and synthesis of vibro impact machines). Riga: Zinatne, 1988, 252 p. (In Russian).

[9] Auzins J., Janushevskis J., Janushevskis A., Kalnins K. Optimisation of designs for natural and numerical experiments, Extended Abstracts of the 6th Int ASMO- UK/ISSMO conference on Engineering Design Optimization. Oxford, UK, 2006. pp. 118-121.

[10] Janushevskis A., Auzins J., Janushevskis J. Viba J. Optimization of subsoic aerodynamic shape by using metamodeling approach. 5th International DAAAM Baltic Conference "Industrial Engineering - Adding Innovation Capacity Of Labour Force And Entrepreneurs". Tallinn, Estonia. 20 - 22nd April. 2006, pp. 41-46.

[11] Auzins J., Janushevskis J., Kalnins K., Kovalska A. Optimization and Metamodeling of Metal Sandwich Panel Structures. Mechanics. Vol.33, Riga, RTU, 2010, pp. 83-88. ISSN 1407-8015.

[12] Auzins J., Janushevskis J. New Sequential Experimental Designs for Metamodeling and Optimization. Scientific Proceedings of RTU: Transport and Engineering. Mechanics. Series 6. vol. 28, Riga, RTU, 2008, pp. 25-38.

[13] Janushevskis A., Meļnikovs A., Auziņš J. Designing and Optimization of New Composite Pallet. Ciência \& Tecnologia dos Materiais, 2015, Special Issue 2015, pp. 115-120.

[14] Auziņš J., Eimanis M. Dynamical Simulation and Optimization of Double-Helical AUV. In: MARINE 2015 : Computational Methods in Marine Engineering VI, Italy, Rome, 15-17 June, 2015. Barcelona: International Center for Numerical Methods in Engineering (CIMNE), 2015, pp. 1128-1139. ISBN 978-84-943928-6-3.

[15] Eimanis M., Auziņš J. Flow Analysis of New Type Propulsion System for UV's. IOP Conference Series: Materials Science and Engineering, 2017, Vol.251: 3rd International Conference on Innovative Materials, Structures and Technologies (IMST 2017), pp. 1-9. ISSN 1757-8981. eISSN 1757-899X.

[16] Tipans I., Viba J., Irbe M., Vutukuru S.K. Analysis of non-stationary flow interaction with simple form objects. Agronomy Research Journal, Vol.17, special issue 1, 2019, pp. 1227-1234. 